\title{
The methodology of natural sciences and its teaching is pedagogical science. (In the case of elementary education)
}

\author{
Alimova Feruza Vahobovna \\ 2 year student of Samarkand State Unoversity, Uzbekistan.
}

\begin{abstract}
The article gives an idea of the connection between the science of natural sciences and pedagogy. The teaching methodology of the theory of the teaching of the subject is taught and taught. Why are the study of natural sciences starting from elementary school? The TB is over.
\end{abstract}

Keywords: Methodology, factors, pedagogy, natural sciences, subject, purpose.

\section{INTRODUCTION}

We all know that the development of natural sciences has its long history. The role of modern botany, biology in the development of natural sciences is immense. The factors that contribute to the development of society are the factors that make life easier. So start the study of natural sciences The first translation literature in the Uzbek language was published in 1919. The first methodologist of the science of fiction was F. Zuyev (1754-1794). We can conclude that, in particular, our great ancestor Abu Rayhon Beruniyah, he showed Globes the opportunity to show the spheres of the world. From 1986, for a transition to four years of primary education for the elementary school, to introduce the world to the universe and to work on natural science and "Environment with the Universe (textbooks, manuals, diaries) on the "Introduction" and "Natural Sciences" courses. In this example, we have an example of rich textbooks for different types of materials for today's elementary school students. you can.

The methodology of teaching natural sciences is a pedagogical fan that explains the content and methods of comprehensively educating children in teaching nature. It is based on research in pedagogy and uses its methods with regard to the content and characteristics of the subject. Through teaching nature to the pupils, the instructor should teach them how to continue their education and not just armed with learning and skills, but the world outlook, will, and character develop mental abilities. Accordingly, it develops the forms and methods of teaching natural science.

\section{THE MAIN PART}

The methodology of teaching natural sciences includes all of the teaching processes from the teacher's preparation to the learning outcomes, including classroom, home, class and extracurricular activities. Specific rules of teaching on the basis of comprehensive teaching of the teaching practice and subsequent creative generalization will be determined and measures to improve it will be developed. Specific measures are being developed to promote the use of subject-oriented teaching on the basis of the direct reception of what is being studied (plants and animals), which provides for a proper perception. In addition, the main topics of this course are the issues of the methods of natural sciences teaching, the history of the theory of history and perspective plans, the methods of organizing extra-curricular activities. The second aspect of the teaching methodology is the methodology of this methodology. The methodologies can use the best methodologies and methodologies for the teaching material of learners to acquire the simplest knowledge of nature and apply them in the future. recipes and advice are not only complex, but also based on science, its principles, the knowledge of the nature of the process of natural sciences teaching. The methodology examines the content of teaching, teaching and learning methods and forms. These sections of the methodology complement each other because they are one. Educational equipment and tools (manuals) are determined by methodology. The methodology answers questions such as how to teach nature, how to teach, how to teach, and how to educate and how to teach. In order to study the theory of the teaching of natural sciences, a base, a room equipped with educational equipment, a wildlife hub and a training and experimental site. The specificity of the material not only determines the uniqueness of the methodology of teaching nature, but also its educational potential. The methodology of teaching the teaching of nature is to teach all the subjects related to the teaching of nature: the integrity 
and development of the teaching content and methods, the consistency of the forms of teaching, and the integrity and development of all the teaching elements. The system of education reaches the consciousness of the learners' knowledge to ensure that the The methodology of teaching natural sciences is a pedagogical fan that teaches the content and methods of comprehensively educating children in the teaching of natural sciences in a didactic and pedagogical manner, which has common principles for all subjects. It is based on research based on pedagogy and uses its methods with regard to the content and characteristics of the subject. The teaching process involves the following topics: the content of the subject, the activities of teachers and students, teaching and learning skills. The methodology of teaching the textbooks not only defines and explains the teaching process, but also produces balcologies, The teaching methodology of the teaching of the teaching of the subject ranges from the preparation of the teacher to the whole of the teaching process, including the learning outcomes, including classroom, home, class and extracurricular activities include. Specific rules of teaching on the basis of comprehensive teaching of the teaching practice and subsequent creative generalization will be determined and measures to improve it will be developed. Specific measures are being taken to promote the use of subject-based teaching in accordance with the law of direct access to plants (animals and plants) - the methods of teaching natural-pedagogical methods, the -path-training and specific methods, the history of the course's organization and perspective plans, the organization of out-of-class activities the methodology of methodology is the methodology of this methodology. The appropriate methodology for the teaching material of the methodologist is used by the pupils acquiring the simplest knowledge of nature and applying it in the future is not just a set of recipes and advice for students, it is also based on the knowledge of the science, its principles, and the principles of the naturalist teaching process. The methodology examines the content of teaching, teaching and learning methods and forms. These chapters of the methodology complement each other because they are one-to-one. The equipment and tools (training aids) are determined by methodology. The methodology answers questions such as how to teach nature, how to teach, how to teach, and how to educate and how to teach. In order to study the theory of the teaching of natural sciences, a base, a room equipped with educational equipment, a wildlife hub and a training and experimental site. The specificity of the material not only determines the uniqueness of the methodology of teaching nature, but also its educational potential. The methodology of teaching the teaching of nature is to teach all the subjects related to the teaching of nature: the integrity of the teaching and methodology, the consistency of the forms of teaching, and the integrity and development of all the educational elements.

The educational process in the school is carried out and the content of the material being studied, the logic of its presentation, teaching methods educates all the educational process in all forms, the teacher itself and its dedication to science. The methodology of the unit employs research methods used in pedagogy. The researcher - a methodologist tracks the process of teaching the nature of the school, analyzes and compares the observed facts, identifies the legitimate links between events, reviews the conclusions and conclusions of the synthesis and, as a consequence, defines the principles of teaching nature. Tracking and experimentation are the most important methods in the field of teaching techniques of nature.

Nowadays integration of a methodology into a science, synthesis - collection and analysis, summarizing, systematization of all scientific materials and their introduction into a single scientific theory are of particular importance. The methodology provides a wide range of opportunities for the teacher to explore a wide variety of methods, methods and tools in the rich treasury of education and upbringing. The methodology of teaching humanities, including physiology, anatomy, hygiene, botany, zoology, geography, agro- meteorology, logic and psychology. The communication with these sciences is reflected in the teacher's ability to master the foundations of these sciences, to distinguish the most important of them, and to explain the material in accordance with the age characteristics of the pupils. The personality development and development of a person, behavior and character. At the same time, the arguments (motives) of one or another activity - reading, work, play, dialogue are of particular importance. Communication evidence should be a part of any course. If it does not include the teacher, it will reduce the potential for knowledge of nature. Thus, a properly established relationship with nature creates a sense of beauty for younger schoolchildren that develops their ability to evaluate their own behavior and self-esteem, and these qualities are characteristic of the moral and ethical nature of behavior understanding of what is happening, responsibilities toward others, and upbringing of responsibilities. In the process of dialogue with nature, companionship and respect for adults are created. Therefore, the teaching methods and the learners are trained in learning the way they organize the learning process, as well as learning about the process of learning the material. The teaching and learning process is carried out and the material The essence, the logic of explaining it, teaching methods educate the whole process of all forms, the teacher himself, and his dedication to science.

\section{CONCLUSION}

Nowadays integration of a methodology into a science, synthesis - collection and analysis, summarizing, systematization of all scientific materials and their introduction 
into a single scientific theory are of particular importance. The methodology provides a wide range of opportunities for the teacher to explore a wide variety of methods, methods and tools in the rich treasury of education and upbringing. The methodology of teaching humanities, including physiology, anatomy, hygiene, botany, zoology, geography, agro- meteorology, logic and psychology. The communication with these sciences is reflected in the teacher's ability to master the foundations of these sciences, to distinguish the most important of them, and to explain the material in accordance with the age characteristics of the pupils. The personality development and development of a person, behavior and character. At the same time, the arguments (motives) of one or another activity - reading, work, play, dialogue are of particular importance. Communication evidence should be a part of any course. If it does not include the teacher, it will reduce the potential for knowledge of nature.

Thus, a properly established relationship with nature creates a sense of beauty for younger schoolchildren that develops their ability to evaluate their own behavior and self-esteem, and these qualities are characteristic of the moral and ethical nature of behavior understanding of what is happening, responsibilities toward others, and upbringing of responsibilities. In the process of dialogue with nature, companionship and respect for adults are created.

\section{REFERENCES}

1. Grigoryans A.G. Natural Science Education T.1992.

2. Nuriddinova M. "Methods of teaching natural sciences" .Educational Manual .2005.

3. Pakulova VM, Kuznetsova M.I. "The methodology of prepodavania prirodovedeniya" 1990. 